\title{
COMPOSIÇÃO FLORÍSTICA E ESTRUTURA DE UM FRAGMENTO DE FLORESTA ESTACIONAL SEMIDECIDUAL ALUVIAL EM VIÇOSA (MG)
}

\author{
Felipe de Araújo Pinto Sobrinho ${ }^{1}$, Alexandre Gabriel Christo ${ }^{2}$, Rejan Rodrigues Guedes-Bruni ${ }^{3}$, \\ Alexandre Francisco Silva ${ }^{4}$ \\ ${ }^{1}$ Eng. Florestal, M.Sc., Doutorando em Geografia Física, USP, São Paulo, SP, Brasil - felipesobrinho@usp.br \\ ${ }^{2}$ Eng. Agrônomo, Mestrando em Botânica, ENBT, Rio de Janeiro, RJ, Brasil - achristo@jbrj.gov.br \\ ${ }^{3}$ Bióloga, Dr ${ }^{\mathrm{a}}$., Instituto de Pesquisas Jardim Botânico do Rio de Janeiro, Rio de Janeiro, RJ, Brasil - rbruni@jbrj.gov.br \\ ${ }^{4}$ Biólogo, Dr., Prof. UFV, Viçosa, MG, Brasil - in memoriam
}

Recebido para publicação: 28/07/2008 - Aceito para publicação: 15/03/2009

\begin{abstract}
Resumo
Este estudo foi desenvolvido em um fragmento de Floresta Estacional Semidecidual aluvial na Fazenda São Luiz, Viçosa (MG). A composição florística e a estrutura florestal foram investigadas através de um censo. No levantamento foram incluídos todos os indivíduos com diâmetro do tronco à altura do peito (DAP) iguais ou maiores que $3 \mathrm{~cm}$. Foram identificados 375 indivíduos em uma área de 0,5 ha, distribuídos em 58 espécies, 46 gêneros e 25 famílias. O índice de diversidade de Shannon $\left(\mathrm{H}^{\prime}\right)$ foi de 3,41. As espécies com maior valor de cobertura (VC) foram Cecropia glaziovii, Nectandra reticulata e Anadenanthera colubrina. O remanescente florestal é composto predominantemente por espécies secundárias iniciais, caracterizando-se como uma etapa seral pioneira, cujo valor de sua conservação se estende à proteção do manancial hídrico a ela associado, onde atua como barreira natural ao assoreamento dos cursos d'água.

Palavras-chave: Florística e estrutura florestal; mata ciliar; estado de Minas Gerais.
\end{abstract}

\begin{abstract}
Floristic composition and structure of a fragment of alluvial Semi-deciduous Tropical Forest in Viçosa $(M G)$. This study was developed in a fragment of riparian forest settled in Fazenda São Luiz, Viçosa (MG). The floristic composition and forest structure was investigated through a census. All individuals with diameter at breast height $(\mathrm{DBH})$ equal to or greater than $3 \mathrm{~cm}$ were evaluated. A total of 375 individuals distributed in 58 species, 46 genera and 25 families were surveyed in 0,5 ha. The Shannon diversity index (H') was 3.41. The species with the highest Cover Value (CV) were Cecropia glaziovii, Nectandra reticulata, Anadenanthera colubrina. This forest remnant is composed mostly by initial secondary species characterizing it in a pioneer seral stage and with conservation value extending to the protection of the associated water resources, acting as a natural barrier to the sedimentation of the water course.

Keywords: Floristic and forest structure; riparian forest; state of Minas Gerais.
\end{abstract}

\section{INTRODUÇÃO}

A Zona da Mata de Minas Gerais, caracterizada por seu relevo acidentado e pela predominância de minifúndios, foi uma das regiões mais atingidas pela ação predatória no estado, devido aos diversos ciclos econômicos. Atualmente, os remanescentes florestais restringem-se a pequenos fragmentos, localizados na maioria das vezes em áreas de difícil acesso e em áreas de preservação permanente protegidas por lei. No caso específico do município de Viçosa, segundo Arruda (1997), um dos principais problemas ambientais é o comprometimento do manancial formado pelo Ribeirão São Bartolomeu, pois a bacia hidrográfica do qual faz parte experimentou intenso processo de substituição da cobertura vegetal original. As cabeceiras destinaram-se à implantação de pastagem e cultivo agrícola, enquanto a parte baixa foi afetada pela crescente urbanização do município. A consequência dessa substituição é o comprometimento da qualidade e da quantidade de água do manancial, colocando em risco sua utilização. 
Nesse cenário, o desmatamento não atingiu somente as áreas propícias às atividades agrícolas e pecuaristas, mas igualmente áreas de matas ciliares que margeavam, no passado, os afluentes e o próprio Ribeirão São Bartolomeu, as quais se encontram, atualmente, praticamente erradicadas.

Alvarenga et al. (2001) destaca importantes funções ambientais desempenhadas pelos ambientes ciliares: manutenção da qualidade da água, estabilidade dos solos e das áreas marginais, regularização do regime hídrico, formação de corredores para o fluxo gênico das espécies vegetais e animais e manutenção do ecossistema aquático.

No contexto da paisagem regional, as formações ciliares estão sob condições muito específicas do ambiente, que acabam por diferenciá-las das formações do interflúvio (não ciliar). Muitas vezes essas diferenças se expressam apenas nos parâmetros quantitativos das populações, e em outras até a fisionomia da vegetação é alterada (RIBEIRO; WALTER, 1998). Diversos autores (OLIVEIRA-FILHO, 1989; OLIVEIRA-FILHO et al., 1990; FELFILI; SILVA JÚNIOR, 1992; SILVA JÚNIOR et al., 1998) destacaram a elevada riqueza florística como característica principal dessas formações. Esse fato, segundo Rodrigues; Nave (2001), se explica pela grande heterogeneidade ambiental dessas áreas, que, influenciadas pela umidade, cria uma condição ecotonal que favorece a formação de um mosaico vegetacional.

O estudo da florística e da fitossociologia dessas florestas ciliares representa o passo inicial para o seu conhecimento, pois, associado ao conhecimento sobre sua estrutura e dinâmica, pode-se construir uma base teórica que subsidie a conservação dos recursos genéticos, a conservação de áreas similares e a recuperação dessas áreas, contribuindo dessa forma para o seu manejo.

Levando em consideração a raridade dessas formações ciliares na região da Zona da Mata Mineira e sua importância ecológica, este estudo objetivou analisar os aspectos florísticos e fitossociológicos de um remanescente de Floresta Estacional Semidecidual Aluvial no município de Viçosa, Minas Gerais, buscando contribuir para o melhor conhecimento e caracterização dessa formação florestal e ao mesmo tempo compará-la com outras formações ciliares do estado. Esse embasamento teórico será útil para subsidiar futuros trabalhos de recuperação, manejo e conservação dessas formações na região da Zona da Mata Mineira, reconhecidas, pela legislação, como prioritárias à conservação da diversidade biológica e dos recursos hídricos associados.

\section{MATERIAIS E MÉTODOS}

\section{Área de estudo}

O presente estudo foi desenvolvido em um fragmento de mata ciliar, situada na Fazenda São Luiz, localizada na coordenada métrica UTM central de E 718707 e N 7700447, com altitude média de 700 metros, no Bairro Romão dos Reis, localizado no município de Viçosa (MG). A área estudada possui aproximadamente 0,5 ha e se distribui ao longo do curso de um riacho que nasce dentro da fazenda e que, mais à jusante, deságua no Ribeirão São Bartolomeu.

O clima da região é do tipo Cwb (subtropical moderado úmido), segundo a classificação de Köppen, apresentando déficit hídrico no período de maio a setembro e um excedente de precipitação entre dezembro e março (GOLFARI, 1975). As médias anuais de precipitação, umidade relativa e temperatura do ar são $1340 \mathrm{~mm}, 80 \%$ e $19{ }^{\circ} \mathrm{C}$, respectivamente (CASTRO et al., 1973).

Os solos no município de Viçosa apresentam predominância de duas classes. Nos topos de morros e encostas predomina o Latossolo Vermelho-Amarelo Álico, enquanto nos terraços a predominância é de solo Podzólico Vermelho-Amarelo Câmbico fase terraço (RESENDE, 1997; CORREIA, 1993).

A microbacia hidrográfica do Ribeirão São Bartolomeu, inserida dentro do município de Viçosa (Figura 1), com sua área total de 5.510 ha, é responsável por parte do abastecimento de água da cidade de Viçosa (FERREIRA; DIAS, 2004), cuja população é de 64.854 habitantes residentes (IBGE, 2005).

A região da microbacia é descrita por Vilela (1998) como de topografia fortemente acidentada, com porções reduzidas de área plana e presença de vales cujos fundos correspondem ao leito maior, periodicamente inundável, seguido de terraços assimétricos onde é mais frequente a prática de agricultura e habitações.

A vegetação local é caracterizada como Floresta Estacional Semidecidual Submontana (OLIVEIRA-FILHO; FONTES, 2000), sendo o termo "aluvial" utilizado nesse estudo de acordo com 
Veloso et al. (1991) e FIBGE (1992), uma vez que o relacionam com as formações ribeirinhas, sobre terraços quaternários, que apresentam características comuns com a vegetação de origem ou do interflúvio, mas que apresentam também particularidades ambientais e vegetacionais que justificam essa divisão. Para fins desse estudo, ao longo do trabalho será adotado o termo "mata ciliar" para designar a floresta estudada.

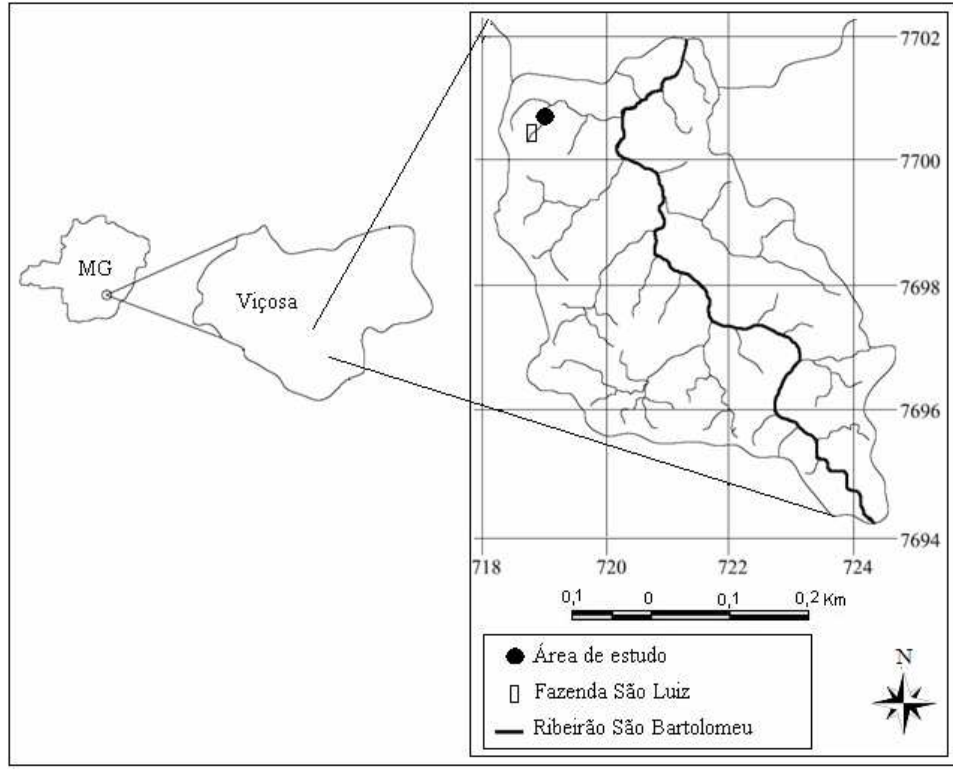

Figura 1. Localização geográfica da área de estudo inserida na bacia do Ribeirão São Bartolomeu, Viçosa (MG). (Adaptado de Ferreira; Dias, 2004).

Figure 1. Geographical localization of the study area inserted in the Ribeirão São Bartolomeu watershed, Viçosa (MG). (Adapted of Ferreira; Dias, 2004).

\section{Inventário da comunidade arbórea}

Para o levantamento florístico-fitossociológico, foi realizado um censo no qual todos os indivíduos com diâmetro à altura do peito maior ou igual a $3 \mathrm{~cm}$ (DAP $\geq 3 \mathrm{~cm}$ ) foram mensurados e identificados taxonomicamente.

O material botânico coletado foi herborizado segundo métodos usuais em botânica, e a identificação foi realizada através de bibliografia especializada, bem como através de comparação com exsicatas do herbário VIC (Departamento de Biologia Vegetal da UFV) e submetidas, quando necessário, aos especialistas nos grupos taxonômicos complexos. O material botânico testemunha foi depositado no Herbário VIC.

O sistema de classificação adotado foi o APG II (2003). A nomenclatura taxonômica foi conferida através das bases de dados do MOBOT (www.tropicos.org.br) e do TreeAtlan1.0 (OLIVEIRAFILHO, 2007).

A diversidade da área de estudo foi estimada através do índice de Shannon (H') (MAGURRAN, 1988). Os parâmetros fitossociológicos abordados foram os de densidade, dominância e índice de valor de cobertura, interpretados segundo Mueller-Dombois; Ellenberg (1974) e Rosot et al. (1982). Utilizou-se o software Fitopac I (SHEPHERD, 1996) para calcular os referidos parâmetros.

A similaridade florística entre a área de estudo e outras sete florestas ciliares no estado foi verificada por meio de uma análise de agrupamento utilizando-se o índice de similaridade de Sørensen (MUELLER-DOMBOIS; ELLEMBERG, 1974). Para tal análise, foi checada a sinonímia botânica de todas as espécies listadas para as áreas.

Para analisar a estrutura vertical da área, utilizou-se o critério recomendado por Souza (1996), em que o perfil vertical é dividido nos seguintes estratos de altura: estrato inferior (EI), estrato médio (EM) e estrato superior (ES), sendo as alturas dos limites entre os três estratos assim calculados: $\mathrm{EI}=\mathrm{H}<$ 
$(\mathrm{Hm}-1 \sigma) ; \mathrm{EM}=(\mathrm{Hm}-1 \sigma) \leq \mathrm{H}<(\mathrm{Hm}+1 \sigma) ; \mathrm{ES}=\mathrm{H} \geq(\mathrm{Hm}+1 \sigma)$, sendo $\mathrm{H}$ a altura total, $\mathrm{Hm}$ a altura média e $\sigma$ o desvio padrão das alturas.

A classificação das espécies em seus respectivos grupos ecológicos baseou-se em estudos realizados na região da Zona da Mata Mineira (LOPES et al., 2002; SILVA et al., 2003; PAULA et al., 2004; ARAÚJO et al., 2006). As espécies cuja classificação sucessional não foi encontrada em literatura ou cujos dados não coincidiam nas diferentes literaturas tiveram sua classificação baseada em observações de campo. Os grupos ecológicos pioneiras (Pi), secundárias iniciais ( $\mathrm{Si}$ ) e secundárias tardias (St) foram definidos segundo Gandolfi et al. (1995).

\section{RESULTADOS E DISCUSSÃO}

\section{Aspectos florísticos e diversidade}

Foram identificadas 58 espécies (Tabela 1), subordinadas a 25 famílias. As famílias com maior riqueza foram: Fabaceae, com 16 espécies (Mimosoideae e Caesalpinioideae com seis cada e Faboideae com quatro); Lauraceae e Euphorbiaceae, com 5; e Meliaceae, com 4. Essas quatro famílias reuniram $51,72 \%$ das espécies amostradas. Meira-Neto et al. (1997), estudando uma Floresta Estacional Semidecidual Aluvial em Ponte Nova, também encontraram Fabaceae (Mimosoideae e Caesalpinoideae) como a mais rica em espécies. Essas quatro famílias destacadas acima também foram as mais ricas nos estudos de Meyer et al. (2004) em uma mata de galeria em Belo Horizonte, e de Pinto et al. (2005), estudando a distribuição de espécies ao longo de nascentes em Lavras (MG). Rodrigues; Nave (2001), analisando 43 trabalhos em florestas ciliares do Brasil extra-amazônico, destacaram igualmente Fabaceae, Lauraceae, Euphorbiaceae e Meliaceae dentre as de maior riqueza específica.

Tabela 1. Relação das espécies arbustivo-arbóreas amostradas na mata ciliar do sítio São Luiz, Viçosa (MG), com seus respectivos parâmetros fitossociológicos e categorias sucessionais: CS: classificação sucessional (Pi: pioneira, Si: secundária inicial, St: secundária tardia e Sc: sem classificação); N.I: número de indivíduos; DR: densidade relativa; DoR: dominância relativa; VC: valor de cobertura.

Table 1. Relation of shrub and tree species sampled in riparian forest of Fazenda São Luiz, Viçosa (MG), with their respective phytossociological parameter and sucessional categories; CS: succecional categories (Pi: pioneer species, Si: early secondary species, St: late secondary species, Sc: without data); NI: number of individuals; DR: relative density; DoR: relative dominance; VC: value covering.

\begin{tabular}{lccccc}
\hline Espécie & CS & NI & DR & DoR & VC\% \\
\hline Cecropia glaziovi Sneth. & $\mathrm{Pi}$ & 30 & 8,00 & 19,21 & 13,61 \\
Nectandra reticulata (Ruiz \& Pav.) Mez. & $\mathrm{St}$ & 41 & 10,93 & 10,29 & 10,61 \\
Anadenanthera colubrina (Vell.) Brenan & $\mathrm{Si}$ & 27 & 7,20 & 10,87 & 9,04 \\
Guarea kunthiana A. Juss. & $\mathrm{St}$ & 32 & 8,53 & 5,66 & 7,10 \\
Boehmeria caudata Sw. & $\mathrm{Pi}$ & 32 & 8,53 & 2,92 & 5,73 \\
Piptadenia gonoacantha (Mart.) J. F. Macbr. & $\mathrm{Si}$ & 12 & 3,20 & 7,39 & 5,30 \\
Nectandra oppositifolia Nees & $\mathrm{Si}$ & 13 & 3,47 & 5,85 & 4,66 \\
Morus alba Linn. & $\mathrm{Pi}$ & 18 & 4,80 & 2,27 & 3,54 \\
Bauhinia forficata Link & $\mathrm{Si}$ & 13 & 3,47 & 2,96 & 3,21 \\
Cassia ferruginea Schrad. Ex DC. & $\mathrm{Si}$ & 11 & 2,93 & 3,37 & 3,16 \\
Inga edulis Mart. & $\mathrm{Si}$ & 2 & 0,53 & 4,44 & 2,49 \\
Croton urucurana Baill. & $\mathrm{Pi}$ & 7 & 1,87 & 2,78 & 2,33 \\
Trichilia pallida Sw. & $\mathrm{Si}$ & 14 & 3,73 & 0,81 & 2,27 \\
Inga marginata Willd. & $\mathrm{Si}$ & 7 & 1,87 & 2,30 & 2,08 \\
Ficus enormis (Mart. ex Miq.) Mart. & $\mathrm{St}$ & 2 & 0,53 & 3,48 & 2,01 \\
Endlicheria paniculata (Spreng.) J. F. Macbr. & $\mathrm{St}$ & 6 & 1,60 & 1,31 & 1,46 \\
Aegiphila sellowiana Cham. & $\mathrm{Pi}$ & 5 & 1,33 & 1,40 & 1,37 \\
Trema micrantha (L.) Blume & $\mathrm{Pi}$ & 5 & 1,33 & 1,29 & 1,31 \\
Aloysia virgata (Ruiz\&Pav.). A. Juss. & $\mathrm{Pi}$ & 8 & 2,13 & 0,44 & 1,29 \\
Piper arboreum Aubl. & $\mathrm{Sc}$ & 7 & 1,87 & 0,28 & 1,08 \\
\hline
\end{tabular}




\begin{tabular}{|c|c|c|c|c|c|}
\hline Xylosma prockia (Turcz.) Turcz. & $\mathrm{Si}$ & 4 & 1,07 & 1,02 & 1,05 \\
\hline Cabralea canjerana (Vell.) Mart. & $\mathrm{Si}$ & 3 & 0,80 & 1,15 & 0,98 \\
\hline Alchornea glandulosa Poepp. \& Endl. & $\mathrm{Si}$ & 6 & 1,60 & 0,33 & 0,97 \\
\hline Piper aduncum L. & Sc & 6 & 1,60 & 0,26 & 0,93 \\
\hline Seguieria langsdorffii Moq. & $\mathrm{Si}$ & 2 & 0,53 & 1,31 & 0,92 \\
\hline Nectandra lanceolata Nees & St & 3 & 0,80 & 0,66 & 0,73 \\
\hline Rollinia sericea (R. E. Fries) R. E. Fries. & $\mathrm{Si}$ & 4 & 1,07 & 0,39 & 0,73 \\
\hline Erythrina verna Vell. & $\mathrm{Pi}$ & 1 & 0,27 & 1,10 & 0,69 \\
\hline Andira fraxinifolia Benth. & $\mathrm{Si}$ & 4 & 1,07 & 0,25 & 0,66 \\
\hline Bauhinia sp1. & $\mathrm{Si}$ & 4 & 1,07 & 0,13 & 0,60 \\
\hline Prunus myrtifolia (L.) Urb. & $\mathrm{Si}$ & 2 & 0,53 & 0,56 & 0,55 \\
\hline Sapium glandulosum (L.) Morong & $\mathrm{Pi}$ & 3 & 0,80 & 0,23 & 0,52 \\
\hline Acacia polyphylla DC. & $\mathrm{Si}$ & 3 & 0,80 & 0,18 & 0,49 \\
\hline Apuleia leiocarpa J.F.Macbr. & $\mathrm{Si}$ & 3 & 0,80 & 0,14 & 0,47 \\
\hline Eugenia gardneriana $\mathrm{O}$. Berg & St & 3 & 0,80 & 0,11 & 0,46 \\
\hline Allophylus racemosus SW. & $\mathrm{Si}$ & 2 & 0,53 & 0,36 & 0,45 \\
\hline Machaerium nyctitans (Vell.) Benth & $\mathrm{Pi}$ & 3 & 0,80 & 0,07 & 0,44 \\
\hline Vernonia diffusa Less. & $\mathrm{Pi}$ & 2 & 0,53 & 0,25 & 0,39 \\
\hline Ocotea pubescens $\mathrm{Mez}$ & St & 2 & 0,53 & 0,20 & 0,37 \\
\hline Croton floribundus Spreng. & PI & 1 & 0,27 & 0,46 & 0,36 \\
\hline Inga striata Benth. & $\mathrm{Si}$ & 1 & 0,27 & 0,46 & 0,36 \\
\hline Cassia sp1. & $\mathrm{Si}$ & 2 & 0,53 & 0,13 & 0,34 \\
\hline Platymiscium pubescens Micheli & St & 2 & 0,53 & 0,10 & 0,32 \\
\hline Alchornea triplinervia Müll. Arg. & $\mathrm{Si}$ & 1 & 0,27 & 0,35 & 0,31 \\
\hline Maytenus evonymoides Reissek & St & 2 & 0,53 & 0,08 & 0,31 \\
\hline Casearia decandra Jacq. & $\mathrm{Si}$ & 2 & 0,53 & 0,07 & 0,30 \\
\hline Cedrela fissilis Vell. & $\mathrm{Si}$ & 1 & 0,27 & 0,05 & 0,16 \\
\hline Bathysa nicholsonii $\mathrm{K}$. Schum. & $\mathrm{Si}$ & 1 & 0,27 & 0,05 & 0,16 \\
\hline Rollinia laurifolia Schltdl. & $\mathrm{Si}$ & 1 & 0,27 & 0,04 & 0,16 \\
\hline Solanum cernuum Vell. & PI & 1 & 0,27 & 0,03 & 0,15 \\
\hline Schinus terebinthifolius Raddi. & PI & 1 & 0,27 & 0,03 & 0,15 \\
\hline Rollinia sylvatica Mart. & $\mathrm{Si}$ & 1 & 0,27 & 0,03 & 0,15 \\
\hline Solanum sp1. & PI & 1 & 0,27 & 0,03 & 0,15 \\
\hline Sorocea bonplandii (Baill.) Burger, Lanj. \& Boer & $\mathrm{Si}$ & 1 & 0,27 & 0,03 & 0,15 \\
\hline Cupania vernalis Cambess. & $\mathrm{Si}$ & 1 & 0,27 & 0,02 & 0,14 \\
\hline Guapira opposita (Vell.) Reitz & $\mathrm{Si}$ & 1 & 0,27 & 0,02 & 0,14 \\
\hline Myrsine coriacea (Sw.) Roem. \& Schult. & PI & 1 & 0,27 & 0,01 & 0,14 \\
\hline Peltophorum dubium Taub. & $\mathrm{Si}$ & 1 & 0,27 & 0,01 & 0,14 \\
\hline
\end{tabular}

O primeiro grupo $(0,31 \%$ de similaridade) foi formado pelos fragmentos de floresta ciliar presentes nas regiões do Alto Rio Grande (MDM, IT, CVB), junto com a floresta ciliar estudada em Belo Horizonte $(\mathrm{GBH})$, todas pertencentes à Floresta Estacional Semidecidual Baixo-Montana (OLIVEIRAFILHO et al., 2000). As três áreas do Alto Rio Grande, por estarem em cotas altitudinais semelhantes (Tabela 1) e pela proximidade geográfica, justificam a assembléia. Um fator que provavelmente está influenciando a presença do remanescente estudado na região metropolitana de Belo Horizonte nesse grupo é que todas essas áreas estão situadas em regiões próximas à disjunção entre as florestas semideciduais e o cerrado (MEYER et al., 2004), recebendo dessa forma influência tanto do Domínio Atlântico quanto do Cerrado, conforme mostra mapa do IBGE (FIBGE, 1992).

De todas as espécies amostradas no presente estudo, 19\% (11) são citadas por Silva (2003) como as mais abundantes em dez levantamentos na Zona da Mata de Minas Gerais: Alchornea triplinervia Müll. Arg., Allophylus racemosus SW., Anadenanthera colubrina (Vell.) Brenan, Apuleia leiocarpa J. F. Macbr., Casearia decandra Jacq., Cassia ferruginea Schrad. Ex DC., Endlicheria paniculata (Spreng.) J. F. Macbr., Machaerium nyctitans (Vell.) Benth, Nectandra lanceolata Nees, Nectandra oppositifolia Nees e Piptadenia gonoacantha (Mart.) J. F. Macbr. 
Dentre as espécies arbustivo-arbóreas amostradas, 18 foram encontradas em pelo menos $24 \%$ (11) dos 43 levantamentos florísticos e fitossociológicos de florestas ciliares do Brasil extra-amazônico, compilados por Rodrigues; Nave (2001). São elas: Guarea kunthiana (11 levantamentos); Aegiphila sellowiana, Acacia poliphylla, Nectandra oppositifolia, Inga marginata (12); Cedrela fissilis (13); Peltophorum dubium, Casearia decandra, Sorocea bomplandii (14); Machaerium nyctitans, Alchornea triplinervia (15); Guapira opposita, Cupania vernalis (16); Croton floribundus, Cabralea canjerana (17); Croton urucurana, Endlicheria paniculata (18) e Trichilia pallida (25). Segundo os autores acima, essas espécies que aparecem nas formações ciliares de diversas regiões do país apresentam um grande potencial para serem utilizadas na recuperação desses ambientes. Vale lembrar ainda que algumas das espécies descritas acima foram destacadas por Oliveira-Filho; Fontes (2000) como espécies "supertramp", com ampla distribuição em várias fitofisionomias de floresta sob o domínio Atlântico no Brasil, sendo elas: Aegiphila sellowiana, Alchornea triplinervia, Cabralea canjerana, Casearia decandra, Cedrela fissilis, Croton floribundus, Endlicheria paniculata e Guapira opposita.

O dendrograma gerado pela análise de agrupamento (Figura 2) entre a área do presente estudo com outras sete áreas ciliares também em Minas Gerais (Tabela 2) mostrou um considerável ajuste à matriz de distância calculada, representada pelo valor do coeficiente cofenético $(\mathrm{rcs}=0,90)$. O valor significativo do rcs $(\alpha=0,05 ; \mathrm{p}<0,0001)$ indica que no processo de síntese de elaboração do dendrograma não houve distorção exarcebada de informação entre a matriz original e a matriz calculada (esperada), sendo possível a um nível de $25 \%$ de similaridade identificar precisamente dois grandes grupos.

Tabela 2. Listagem dos oito fragmentos de floresta ciliar no estado de Minas Gerais, utilizados para a análise de similaridade florística. $\mathrm{N}$ : número de espécies, $\mathrm{NC}=$ número de espécies em comum e H'= índice de diversidade de Shannon.

Table 2. List of the eight fragments of riparian forest in Minas Gerais, used to the analyse of floristic similarity. N: number of species, NC: shared species, H': Shannon diversity index.

\begin{tabular}{llclccc}
\hline Sigla & Local & Altitude & Autores & N & NC & H' \\
\hline ASB & Presente estudo & $700 \mathrm{~m}$ & - & 59 & - & 3,41 \\
GV & Viçosa & $650-700 \mathrm{~m}$ & Meira-Neto et al. (2003) & 48 & 13 & - \\
RP & Rio Piranga - Ponte Nova & $500 \mathrm{~m}$ & Meira-Neto et al. $(1997)$ & 58 & 12 & 3,25 \\
GBH & Belo Horizonte & $950-1000 \mathrm{~m}$ & Meyer et al $(2004)$ & 97 & 18 & - \\
CVB & Córrego Vilas Boas - Lavras & $950-1200 \mathrm{~m}$ & Oliveira-Filho et al. (1994) & 119 & 17 & 4,20 \\
TM & Três Marias & $475-510 \mathrm{~m}$ & Carvalho et al. 2005 & 117 & 4 & 3,73 \\
IT & Itutinga & $920 \mathrm{~m}$ & Van den Berg et al. $(2000)$ & 162 & 18 & 3,92 \\
MDM & Madre de Deus de Minas & $900-950 \mathrm{~m}$ & Vilela et al. (2000) & 116 & 9 & 3,79 \\
\hline
\end{tabular}

O segundo grupo (0,30\%) abrangeu a área do presente estudo (ASB) com outras duas (RP e GV), todas situadas na Zona da Mata Mineira, onde predomina a típica Floresta Estacional Semidecidual Submontana. Fatores como proximidade geográfica, altitude e padrão pluviométrico provavelmente estão influenciando nessa assembléia. Essas áreas estão sob maior influência das vertentes interiores da Serra do Mar (VAN DEN BERG et al., 2000), tendo assim maior influência do Domínio Atlântico (FIBGE, 1992).

A maior similaridade $(0,43 \%)$ entre a área do presente estudo com a mata de galeria $(\mathrm{GV})$, situada no mesmo município, se justifica pela maior proximidade, semelhança de altitude e influência da mesma matriz vegetacional, caracterizada principalmente pelos fragmentos de Floresta Estacional Semidecidual restritos aos topos de morro. Essas duas comunidades compartilham 13 espécies: Alchornea glandulosa, Cabralea canjerana, Cecropia glaziovii, Endlicheria paniculata, Guarea kunthiana, Machaerium nyctitans, Nectandra oppositifolia, Piper aduncum, Rollinia laurifolia, Schinus terebinthifolius, Solanum cernuum, Sorocea bomplandii, Trichilia pallida. Exceto Guarea kunthiana, todas as demais espécies citadas possuem ampla ocorrência nos fragmentos florestais da região.

A área estudada em Ponte Nova (RP), apesar de também estar inserida no grupo 2, apresentou uma menor similaridade com o presente estudo (0,30\%), compartilhando as seguinte espécies: Anadenanthera colubrina, Apuleia leiocarpa, Cassia ferruginia, Cecropia glaziovii, Croton floribundus, Cupania vernalis, Eugenia gardineriana, Machaerium nyctitans, Piper arboreum, Piptadenia gonoacantha, Solanum cernuum e Trichilia pallida. 


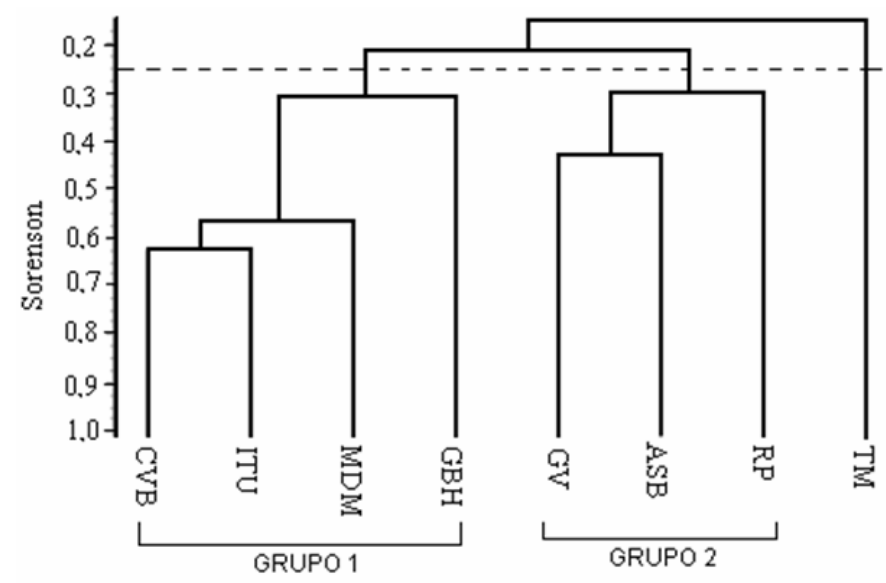

Figura 2. Dendrograma de similaridade florística obtido pelo método de média não ponderada (UPGMA), com base no índice de Sørensen, entre oito fragmentos de floresta ciliar no estado de Minas Gerais. CVB: Córrego Vilas Boas, Lavras; ITU: Itutinga; MDM: Madre de Deus de Minas; GBH: Belo Horizonte; GV: Viçosa; ASB: Viçosa (presente trabalho); RP: Ponte Nova; TM: Três Marias.

Figure 2. Dendrogram of floristics similarity obtained by the Unweighted Pair Group Method with Arithmetic mean (UPGMA), based on the Sørensen index, among eight riparian forest fragments in Minas Gerais. CVB: Córrego Vilas Boas, Lavras: ITU: Itutinga; MDM: Madre de Deus de Minas; GBH: Belo Horizonte; GV: Viçosa; ASB: Viçosa (present study); RP: Ponte Nova; TM: Três Marias.

A área ciliar estudada em Três Marias (TM) manteve-se isolada dos demais grupos. Esse resultado se explica em parte por essa área estar inserida em uma região de transição entre a Floresta Estacional Decidual e o Cerrado, recebendo uma maior influência desse último.

No geral, as áreas apresentaram uma baixa similaridade florística, tendo a maior similaridade ocorrida no nível de 62\% (ITU + CVB). Rodrigues; Nave (2001) ressaltam que a acentuada diversidade que existe nos ambientes ciliares, com valores de similaridade baixos mesmo para áreas próximas, ocorre devido à elevada heterogeneidade ambiental associada ao estado de conservação ou degradação dos remanescentes, ao tipo vegetacional, ao tamanho da faixa ciliar, ao nível do lençol freático e à distância entre os fragmentos, entre outros fatores.

O valor do índice de diversidade de Shannon (H’) para a área foi de 3,411 nats/indivíduo e está entre os valores encontrados para os fragmentos de Floresta Estacional Semidecidual da região, que variam de 3,2 a 4,2 segundo Meira-Neto; Martins (2000).

Quando comparado aos índices de diversidade encontrados nas matas ciliares do Alto Rio Grande (MDM - H' = 3,79; IT $-\mathrm{H}^{\prime}=3,92$; CVB $\left.-\mathrm{H}^{\prime}=4,20\right)$ e ao da mata ciliar estudada em Três Marias $\left(H^{\prime}=3,73\right)$, percebe-se uma menor diversidade na área do presente estudo. As alterações antrópicas ocorridas na presente área (extração de madeira e fogo), juntamente com a entrada do gado, provavelmente contribuíram para a redução da diversidade local.

\section{Estrutura da comunidade arbórea}

Foram amostrados 375 indivíduos, perfazendo uma densidade total (DT) de 750 indivíduos por hectare. O diâmetro médio da população foi de $11,91 \mathrm{~cm}$, totalizando uma área basal de $6,89 \mathrm{~m}^{3}$ e altura média de 8,16 m. Meira-Neto et al. (1997), estudando uma mata de galeria em Ponte Nova, também na Zona da Mata, encontraram uma densidade total de 1.360 indivíduos por hectare, com diâmetro médio de $11,25 \mathrm{~cm}$ e altura média de 8,4 metros - valores muito próximos aos encontrados neste estudo.

No que concerne à densidade das famílias, destacam-se Fabaceae, com 192 indivíduos por hectare (Mimosoideae: 104; Caesalpinioideae: 68; Faboideae: 20), Lauraceae, com 130, e Meliaceae, com 100. Isso representa $56,26 \%$ do total dos indivíduos por hectare. 
As espécies com maiores densidades absolutas e relativas foram Nectandra reticulata, Guarea kunthiana, Boehmeria caudata, Cecropia glaziovii, Anadenanthera colubrina e Morus alba (Tabela 1). Nectandra reticulata e Guarea kunthiana, secundárias tardias, apresentaram grande densidade de indivíduos jovens, com diâmetros menores do que $20 \mathrm{~cm}$, restritos às áreas mais baixas do fragmento, próximas ao curso d'água e, muitas vezes, presentes em locais que sofrem alagamento em períodos de maior pluviosidade. Guarea kunthiana apareceu também com elevada densidade em uma floresta periodicamente inundada em Viçosa, no estudo de Meira-Neto et al. (2003). Esse táxon, quando analisado em outros ambientes menos úmidos, para a mesma região, aparece em poucos estudos e, quando presente, com densidade bem baixa. Toniato et al. (1998) destaca Guarea kunthiana como típica, ou pelo menos comum, em florestas higrófilas no estado de São Paulo.

Nectandra reticulata, igualmente pouco comum nos estudos em fragmentos florestais na região de Viçosa, provavelmente segue o mesmo padrão de preferência por áreas mais úmidas. Oliveira-Filho et al. (1994) destacam a importância da umidade como um fator determinante na distribuição das espécies. Outras espécies com baixas densidades e mais restritas às áreas próximas aos cursos d'água foram Piper aduncum, $P$. arboreum - caracterizadas por indivíduos arbustivos, presentes em áreas sombreadas - e Bauhinia forficata, Inga marginata, I. striata e I. edulis, todas tipicamente secundárias iniciais.

As espécies que apresentaram maiores áreas basais e, consequentemente, maiores dominâncias foram Cecropia glaziovii, Anadenanthera colubrina, Nectandra reticulata, Piptadenia gonoacantha, Nectandra oppositifolia e Guarea kunthiana (Tabela 1).

Cecropia glaziovii se destacou pela presença de indivíduos adultos com grandes diâmetros e alturas superiores a $10 \mathrm{~m}$ distribuídos por todo o fragmento. Foram poucos os indivíduos com diâmetros pequenos, sendo todos eles restritos a locais mais expostos à luz e cujo comportamento já fora comentado por Araújo et al. (2006). Para esses autores, trata-se de um comportamento típico de espécies pioneiras, que tendem a ser substituídas no processo sucessional, evento este evidenciado pelo baixo recrutamento de indivíduos jovens no fragmento estudado.

Anadenanthera colubrina, Piptadenia gonoacantha e Nectandra oppositifolia, apesar de indivíduos maduros, com elevados diâmetros, apresentaram também indivíduos jovens, presentes nas menores classes diamétricas, crescendo por todo o fragmento, um indicador seguro de que estão em processo de recrutamento e participando da regeneração da floresta.

Quanto ao valor de cobertura (VC), Cecropia glaziovii $(13,61 \%)$ seguida por Nectandra reticulata $(10,61 \%)$ e Anadenanthera colubrina $(9,04 \%)$ apresentam os maiores valores percentuais. Cecropia glaziovii, destaca-se em função do elevado diâmetro dos indivíduos amostrados, o que resultou no alto valor de dominância. Já Nectandra reticulata destacou-se devido a sua elevada densidade.

O estudo de Meira-Neto et al. (2003), no mesmo município, utilizando a mesma metodologia de coleta, em uma mata ciliar, encontrou diferentes espécies se destacando quanto ao valor de cobertura, entre elas Talauma ovata A. St.-Hil., Euterpe edulis Mart, Erythrina falcata Benth. e Schinus terebinthifolius. A grande densidade das espécies Talauma ovata e Euterpe edulis, ambas secundárias tardias, pode ser um indicativo de que o remanescente estudado se encontra em um estágio mais tardio de sucessão.

A distribuição diamétrica seguiu o padrão de "J" invertido (Figura 3), o que, segundo Harper (1990), é característica física de florestas nativas. De todos os indivíduos amostrados, 53,7\% estão inseridos na primeira classe diamétrica $(3,2-10 \mathrm{~cm})$, indicando um forte incremento de indivíduos jovens na comunidade. Apenas três indivíduos atingiram diâmetro maior que $60,1 \mathrm{~cm}$.

A estratificação vertical da população indicou uma maior concentração de indivíduos no estrato médio da floresta (Figura 4). A altura média da população foi de 7,5 metros, e o estrato inferior contou principalmente com as espécies típicas de sub-boque, entre elas Piper aduncum, P. arboreum, Boehmeria caudata e Inga marginata. As espécies Apuleia leiocarpa e Cecropia glaziovii apresentaram alguns indivíduos com altura total de 22 metros, tendo suas copas sobressaído sobre as demais.

O resultado da classificação sucessional das espécies (Figura 5) mostra a predominância do grupo ecológico de secundárias iniciais, tanto quando analisado o percentual de densidade (40\%) como o de riqueza de espécies $(53,4 \%)$. A este se segue o grupo das pioneiras. A elevada concentração de indivíduos nos estágios iniciais de regeneração indica que a comunidade estudada encontra-se em uma etapa seral pioneira (ARAÚJO et al., 2006). 


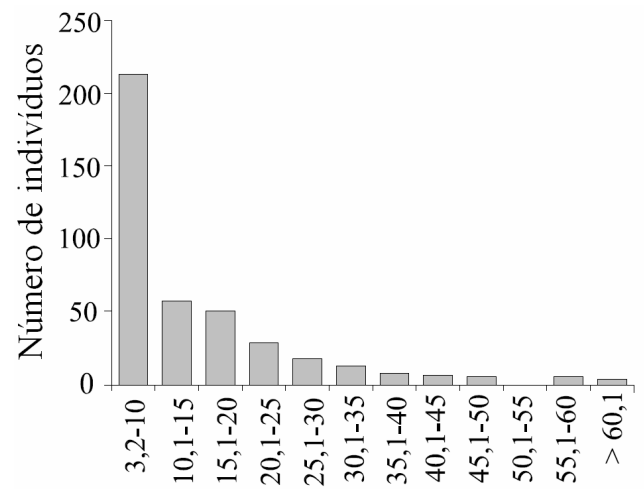

Classes de diâmetro $(\mathrm{cm})$

Figura 3. Distribuição da frequência de indivíduos em classes diamétricas dos indivíduos arbustivos e arbóreos amostrados na mata ciliar da Fazenda São Luiz, Viçosa (MG).

Figure 3. Distribution of individual frequency in diametric classes of shrub and tree species sampled in riparian forest of Fazenda São Luiz, Viçosa (MG).

Estudos sobre sucessão, entre eles os de Silva et al. (2003), Paula et al. (2004), Silva et al. (2004), Higuchi et al. (2006), também têm encontrado a predominância de espécies secundárias iniciais. Observa-se, assim, que, para a região de Viçosa, os fragmentos em sua maioria são alterados e se encontram em fases próximas no processo de regeneração natural.

Ferreira; Dias (2004) aconselham que em um futuro projeto de reflorestamento para as zonas ripárias existentes ao longo do Ribeirão São Bartolomeu, devido ao atual estado de degradação, deve ser levado em conta um modelo sucessional que se baseie na combinação de espécies de diferentes grupos sucessionais, uma vez que espécies de início de sucessão, não tolerantes a sombra, devem fornecer condições ecológicas favoráveis para as espécies mais tardias.

Nesse contexto, partindo do pressuposto de que para conservar é preciso conhecer, os estudos florísticos e fitossociológicos combinados com a caracterização sucessional das espécies de um determinado remanescente formam uma base teórica de fundamental importância para subsidiar quaisquer iniciativas voltadas para a conservação ou a recuperação da vegetação local, esforço este que pode ser auxiliado por comparações com áreas que resguardam características similares à que se pretende estudar.

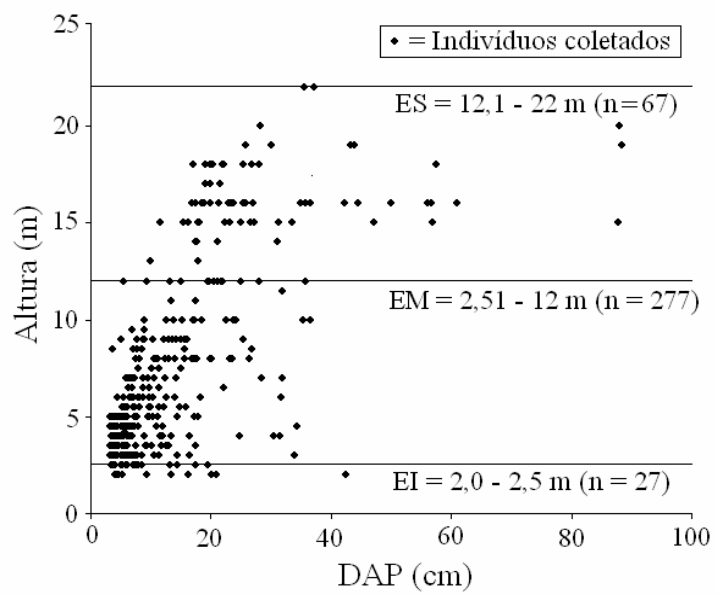

Figura 4. Relação alométrica entre diâmetro e altura dos indivíduos arbóreos arbustivos e arbóreos amostrados na mata ciliar da Fazenda São Luiz, Viçosa (MG). ES: Estrato superior; EM: Estrato médio; EI: Estrato inferior; n: número de indivíduos.

Figure 4. Alometric relation between diameter and height of shrub and tree species sampled in riparian forest of Fazenda São Luiz, Viçosa (MG). ES: low stratum; EM: Middle stratum; ES: Upper stratum. 


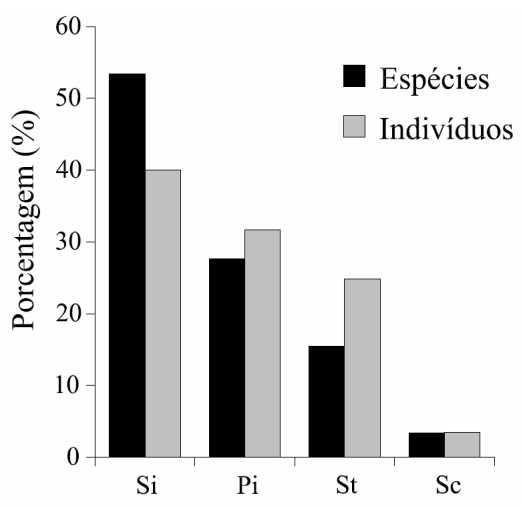

Figura 5. Distribuição da porcentagem de espécies e indivíduos arbóreos amostrados na mata ciliar da Fazenda São Luiz, Viçosa (MG), em categorias sucessionais. Pi: Pioneira; Si: Secundária inicial; St: secundária tardia; SC: sem classificação.

Figure 5. Distribution of the percentage of species and tree individuals, found in the present study. Pi: pioneer species; Si: early secondary species; St: late secondary species; Sc: without classification.

\section{CONCLUSÃO}

- Leguminosae, Lauraceae, Euphorbiaceae e Meliaceae apresentaram uma maior riqueza específica. Esse padrão tem se repetido não só em áreas ciliares no estado de Minas Gerais, mas também em muitos estudos em áreas de vegetação ciliar no Brasil extra-amazônico.

- Algumas espécies encontradas no presente estudo - Guarea kunthiana, Aegiphila sellowiana, Acacia poliphylla, Nectandra oppositifolia, Inga marginata, Cedrela fissilis, Peltophorum dubium, Casearia decandra, Sorocea bomplandii, Machaerium nyctitans, Alchornea triplinervia, Guapira opposita, Cupania vernalis, Croton floribundus, Cabralea canjerana, Croton urucurana, Endlicheria paniculata e Trichilia pallida -, devido às suas amplas ocorrências em áreas ciliares no Brasil extraamazônico, possuem um grande potencial para serem utilizadas na restauração desses ambientes.

- A análise da similaridade florística entre fragmentos de floresta ciliar no estado de Minas Gerais indicou a existência de dois grupos. Fatores como proximidade geográfica, altitude e influência de diferentes regiões fitogeográficas provavelmente foram determinantes nesse resultado. As maiores similaridades ocorreram entre as três áreas presentes na região do Alto Rio Grande, todas acima de 900 metros de altitude.

- A classificação sucessional das espécies inventariadas, por sua vez, reforça a caracterização da vegetação como floresta em estágio intermediário de regeneração, com base na predominância de espécies secundárias iniciais, tais como Anadenanthera colubrina, Bauhinia forficata, Nectandra oppositifolia, Piptadenia gonoacantha e Trichilia pallida, entre outras. Essa mata ciliar vem desempenhando um importante papel na proteção do manancial hídrico a ela associado, atuando como barreira natural, uma vez que, através de análises visuais feitas em campo, não indicaram sinais de erosão e consequente assoreamento do curso d'água.

- A má conservação dos remanescentes de florestas ciliares e a insuficiência de dados disponíveis para essas formações na região da Zona da Mata Mineira dificultam a proposição de modelos para sua restauração ecológica, tornando urgente a criação de parcerias e políticas públicas capazes de fomentar o binômio conservação e uso sustentado dos recursos florestais.

\section{REFERÊNCIAS}

ALVARENGA, A. P.; BOTELHO, S. A.; PEREIRA, I. M. Avaliação da regeneração natural na recomposição de matas ciliares em nascentes na região sul de Minas Gerais. Cerne, Lavras, v. 12, n. 4, p. 360-372, 2006. 
APG II. An update of APG classification for the orders and families of flowering plants. Linnean Society. Botanical Journal, London,, v. 141, p. 399-436, 2003.

ARAÚJO, F. S.; MARTINS, S. V.; MEIRA-NETO, J. A.; LANI, J. L.; PIRES, I. E. Estrutura da vegetação arbustivo-arbórea colonizadora de uma área degradada por mineração de caulim. Brás Pires, MG. Revista Árvore, Viçosa, MG, v. 30, n. 1, p. 107-116, 2006.

ARRUDA, P. R. Uma contribuição ao estudo ambiental da bacia hidrográfica do ribeirão São Bartolomeu, Viçosa, Minas Gerais. 108 f. Dissertação (Mestrado em Ciência Florestal) - Universidade Federal de Viçosa, Viçosa, MG, 1997.

CARVALHO, D. A.; OLIVEIRA FILHO, A. T.; ENIVANIS A. VILELA, E. A.; CURI, N.; VAN DEN BERG, E.; FONTES, M. A. L.; BOTEZELLI, L. Distribuição de espécies arbóreo-arbustivas ao longo de um gradiente de solos e topografia em um trecho de floresta ripária do Rio São Francisco em Três Marias, MG, Brasil. Revista Brasileira de Botânica, São Paulo, v. 28, n. 2, p. 329-345, 2005.

CASTRO, P. S.; VALENTE, O. F., COELHO, D. T. Interceptação da chuva por mata natural secundária na região de Viçosa, MG. Revista Ârvore, Viçosa, MG, v. 7, p. 76-88, 1973.

CORREIA, G. F. Modelo de evolução mineralógica da fração argila de solos de planalto de Viçosa. 87 f. Dissertação (Mestrado em Ciência Florestal) - Universidade Federal de Viçosa, Viçosa, MG, 1993.

FELFILI, J. M.; SILVA JÚNIOR, M. C. Floristic composition, phytosociology and comparison of cerrado and gallery florests at Fazenda Água Limpa, Federal District, Brazil. In: FURLEY, P. A.; RATTER, J. A.; PROCTOR, J. A. (Eds.). Nature and dynamics of forest savanna boundaries. London: Chapman \& Hall, 1992. p. 393-415.

FERREIRA, D. A. C.; DIAS, H. C. T. Situação atual da mata ciliar do ribeirão São Bartolomeu em Viçosa, MG. Revista Árvore, Viçosa, MG, v. 28, n. 4, p. 617-623, 2004.

FUNDAÇÃO DO INSTITUTO BRASILEIRO DE GEOGRAFIA E ESTATÍSTICA (FIBGE). Mapa da vegetação do Brasil., Rio de Janeiro, 1992. 92 p.

GANDOLFI, S.; LEITÃO FILHO, H. F.; BEZERRA, C. L. F. Levantamento florístico e caráter sucessional das espécies arbustivo-arbóreas de uma Floresta Semidecídua no município de Guarulhos, SP. Revista Brasileira de Biologia, Rio de Janeiro, v. 55, p. 753-767, 1995.

GOLFARI, L. Zoneamento ecológico do estado de Minas Gerais para reflorestamento. Belo Horizonte. Centro de Pesquisa florestal da região do cerrado - PRODEPEF (PNUD, FAO/ IBDFBRA/71/545), 1975. 65 p. (Série técnica, n. 3).

HARPER, J. L. Population biology of plants. London: Academic. 1990. 892 p.

HIGUCHI, P.; REIS. M. G. F.; REIS, G. G.; PINHEIRO, A. L.; SILVA, C. T.; OLIVEIRA, C. H. R. Composição florística da regeneração natural de espécies arbóreas ao longo de oito anos em um fragmento de floresta Estacional Semidecidual, em Viçosa, MG. Revista Árvore, Viçosa, MG, v. 30, n. 6, p. 893-904, 2006.

INSTITUTO BRASILEIRO DE GEOGRAFIA E ESTATÍSTICA - IBGE. Censo demográfico - 2000. Disponível em: <http://www.ibge.gov.br/>. Acesso em: outubro/2005.

LOPES, W. P.; PAULA, A.; SEVILHA, A. C.; SILVA, A. F. Composição da flora arbórea de um trecho de Floresta Estacional no Jardim Botânico da Universidade Federal de Viçosa (face sudoeste), Viçosa, Minas Gerais. Revista Árvore, Viçosa, MG, v. 26, n. 3, p. 339-347, 2002.

MAGURRAN, A. E. Ecological diversity and its measurement. New Jersey:Princeton University Press, 1988. $192 \mathrm{p}$.

MEIRA-NETO, J. A. A.; MARTINS, F. Estrutura da Mata da Silvicultura, uma floresta Estacional Semidecidual Montana no município de Viçosa - MG. Revista Árvore, Viçosa, MG, v. 24, n. 2, p. 151160, 2000. 
MEIRA-NETO, J. A. A.; REGO, M. M.; COELHO, D. J. S.; RIBEIRO, F. G. Origem, sucessão e estrutura de uma floresta de galeria periodicamente alagada em Viçosa-MG. Revista Árvore, Viçosa, MG, v. 27, n. 4, p. 561-574, 2003.

MEIRA-NETO, J. A. A.; SOUZA, A. L.; SILVA, A. F.; PAULA, A. Estrutura de uma floresta estacional semidecidual aluvial em área de influência da Usina Hidrelétrica do Pilar, Ponte Nova, Zona da Mata de Minas Gerais. Revista Árvore, Viçosa, MG, v. 21, p. 213-219, 1997.

MEYER, S. T.; SILVA, A. F.; JÚNIOR, J. M.; MEIRA-NETO, J. A. Composição florística da vegetação arbórea de um trecho de floresta de galeria do Parque Estadual do Rola-Moça na Região Metropolitana de Belo Horizonte, MG, Brasil. Acta Botanica Brasilica, Porto Alegre, v. 18, n. 4, p. 701-709, 2004.

MISSOURI BOTANICAL GARDEN. W3 Tropicos: Vascular Tropicos Nomenclatural Database. Acesso emnovembro de 2008. Disponível em: <http://www.mobot.org/W3T/Search/vast.html>.

MUELLER-DOMBOIS, D.; ELLEMBERG, H. Aims and methods of vegetation ecology. New York: J. Wiley \& Sons. 1974. 547 p.

OLIVEIRA-FILHO, A. T. Composição florística e estrutura comunitária da floresta de galeria do córrego da Paciência, Cuiabá (MT). Acta Botanica Brasílica, Porto Alegre, v. 3, n. 1, p. 91-112, 1989.

OLIVEIRA-FILHO, A. T de. TreeAtlan: Flora arbórea da Mata Atlântica domínios adjacentes: Um banco de dados envolvendo geografia, diversidade e conservação.. Disponível em: <http://www.treeatlan.dcf.ufla.br>. Acesso em: maio/2007.

OLIVEIRA-FILHO, A. T.; ALMEIDA, R. J.; MELlO, J. M.; GAVILANES, M. L. Estrutura fitossociológica e variáveis ambientais em um trecho da mata ciliar do córrego dos Vilas Boas, Reserva Biológica do Poço Bonito, Lavras (MG). Revista Brasileira de Botânica, São Paulo, v. 17, n. 1, p. 67$85,1994$.

OLIVEIRA-FILHO, A. T.; FONTES, M. A. L. Patterns of floristic differentiation among Atlantic forests in south-eastern Brazil and the influence of climate. Biotropica, Saint Louis, v. 32, p. 793-810, 2000.

OLIVEIRA-FILHO, A. T.; RATTER, J. A.; SHEPHERD, G. J. Floristic composition and community structure of a Central Brazilian gallery forest. Flora, London, v. 184, n. 2, p. 103-117, 1990.

PAULA, A.; SILVA, A. F.; JÚNIOR, P. M.; SANTOS, F. A. M.; SOUZA, A. L. Sucessão ecológica da vegetação arbórea em uma Floresta Estacional Semidecidual, Viçosa, MG, Brasil. Acta Botanica Brasilica, Porto Alegre, v. 18, n. 3, p. 407-423. 2004.

PINTO, L. V. A.; DAVIDE, A. C.; BOTELHO, S. A.; OLIVEIRA-FILHO, A. T.; MACHADO, E. L. M. Distribuição das espécies arbóreo-arbustiva ao longo do gradiente de umidade do solo de nascentes pontuais da Bacia Hidrográfica do Ribeirão Santa Cruz, Lavras, MG. Cerne, Lavras, v. 11, n. 3, p. 294305. 2005.

REZENDE, S. B. Estudo de crono-toposeqüência em Viçosa - Minas Gerais. 71 f. Dissertação (Mestrado em Solos e Nutrição de Plantas) - Universidade Federal de Viçosa, Viçosa, MG, 1997.

RIBEIRO, J. F.; WALTER, B. M. T. Fitofisionomias do bioma cerrado. In: SANO, S. M.; ALMEIDA, S. P. Cerrado: ambiente e flora. Planaltina: Embrapa- CPAC, 1998.

RODRIGUES, R. R.; NAVE, A. G. Heterogeneidade florística das matas ciliares. In: RODRIGUES, R. R.; LEITÃO-FILHO, H. F. (Eds.). Matas Ciliares: Conservação e Recuperação. 2. ed. São Paulo: Edusp, Fapesp, 2001.

ROSOT, N. C.; MACHADO, S. A.; FIGUEIREDO- FILHO, A. Análise estrutural de uma floresta tropical como subsídio básico para elaboração de um plano de manejo florestal. In: CONGRESSO NACIONAL SOBRE ESSÊNCIAS NATIVAS, 1982, São Paulo. Anais... São Paulo, Instituto Florestal. 1982. p. 468-490. 
SHEPHERD, G. J. FITOPAC I; Manual do usuário. Campinas: Universidade Estadual de Campinas . Departamento de Botânica, , 1996. 96 p.

SILVA, A. F.; OLIVEIRA, V. R.; SANTOS, N. R. L. E PAULA, A.. Composição florística e grupos ecológicos das espécies de um trecho de floresta semidecídua submontana da fazenda São Geraldo, Viçosa-MG. Revista Árvore, Viçosa, MG, v. 27, n. 3, p. 311-319, 2003.

SILVA, C. T.; REIS, G. G.; REIS, M. G. F.; SILVA, E. CHAVES, R. A. Avaliação temporal da florística arbórea de uma floresta secundária no município de Viçosa, Minas Gerais. Revista Árvore, Viçosa, MG, v. 28, n. 3, p. $429-441,2004$.

SILVA JUNIOR, M. C.; NOGUEIRA, P. E. E FELFILI, J. M. Flora Lenhosa das matas de galeria no Brasil Central. Boletim do Herbario Ezechias Paulo Heringer, Brasília, DF, , v. 5, p. 57-76. 1998.

SOUZA, A. L.; MEIRA-NETO, J. A. A.; SCHETTINO, S. Avaliação fitossociológica. Viçosa, MG,: SIF/DEF. 1996. 289 p. Relatório final do Convênio SIF/BSCEL32STO25.

TONIATO, M. T. Z.; LEITÃO FILHO, H. F.; RODRIGUES, R. R. Fitossociologia de um remanescente de floresta higrófila (mata de brejo) em Campinas, SP. Revista Brasileira de Botânica, São Paulo, v. 21 n. 2, 1998 .

VAN DEN BERG, E.; OLIVEIRA-FILHO, A. T. Composição florística e estrutura fitossociológica de uma floresta ripária em Itutinga, MG e comparação com outras áreas. Revista Brasileira de Botânica, São Paulo, v. 23, n. 3, p. 231-253, 2000.

VELOSO, H. P.; RANGEL FILHO, A. L. R.; LIMA, J. C. Classificação da vegetação brasileira, adaptada a um sistema universal. Rio de Janeiro: IBGE, 1991. 123 p.

VILELA, M. Uso de diferentes métodos de retificação geométrica e classificação digital de uma imagem TM/LANDSAT - 5. 118 f. Dissertação (Mestrado em Ciência Florestal) - Universidade Federal de Viçosa, Viçosa, MG, 1998.

VILELA, E. A.; OLIVEIRA-FILHO, A. T.; CARVALHO, D. A.; GUILHERME, F. A. G.; APPOLINÁRIO, V. Caracterização estrutural de floresta ripária do Alto Rio Grande, em Madre de Deus de Minas Gerais, MG. Cerne, Lavras, v. 6, n. 2, p. 41-54, 2000. 